\title{
Successful Treatment of Suborbital Pyogenic Granuloma with Topical Imiquimod
}

\author{
George Badavanis ${ }^{1}$, Efstathia Pasmatzi ${ }^{2}$, Alexandra Monastirli1 ${ }^{1,2}$, Dionysios Tsambaos ${ }^{1,2}$ \\ ${ }^{1}$ Center for Dermatologic Diseases, Limassol, Cyprus \\ ${ }^{2}$ Department of Dermatology, University of Patras, Patras, Greece \\ Email: pasmatzi@otenet.gr
}

How to cite this paper: Badavanis, G., Pasmatzi, E., Monastirli, A. and Tsambaos, D. (2018) Successful Treatment of Suborbital Pyogenic Granuloma with Topical Imiquimod. Case Reports in Clinical Medicine, 7, 1-6.

https://doi.org/10.4236/crcm.2018.71001

Received: December 8, 2017

Accepted: January 6, 2018

Published: January 9, 2018

Copyright $\odot 2018$ by authors and Scientific Research Publishing Inc. This work is licensed under the Creative Commons Attribution International License (CC BY 4.0).

http://creativecommons.org/licenses/by/4.0/

(c) (†) Open Access

\begin{abstract}
Pyogenic granuloma (PG) is a benign vascular proliferation of the skin and mucosae, that has been treated with different regimens with variable success and recurrence rates; however, the management of PG still remains a challenging issue, particularly in children and in adult cases with lesions localized at sites difficult to access. Imiquimod, a member of the imidazoquinoline family of immune response modifiers, is a topically applicable TLR-7/8 agonist that reveals potent antiviral, antitumor, immunoregulatory and antiangiogenic properties. In the present paper we report the case of a 9-year old boy with suborbital pyogenic granuloma, successfully treated with topical daily application of imiquimod $5 \%$ cream without occlusion. 8 weeks after onset of topical imiquimod treatment a complete resolution of the lesion without any scarring was observed. No systemic side effects were seen and the patient remained well throughout the course of therapy. He is presently completing a 15-month follow-up and has revealed no relapse. The findings of the present study suggest that topical imiquimod is a safe, effective and well-tolerated treatment for PG in children, even at difficult to treat areas like the suborbital region.
\end{abstract}

\section{Keywords}

Pyogenic Granuloma, Imiquimod, Children, Angiogenesis

\section{Introduction}

Pyogenic granuloma (PG) (granuloma telangiectaticum or lobular capillary haemangioma) is a benign vascular proliferation of skin and mucosae. Typically, it presents as a mostly solitary, rapidly developing, hemorrhagic and ulceration-prone, purple, angiomatous papule or nodule usually located on the face, fingers, toes and trunk, and on mucous membranes, as well. Predisposing factors 
for the occurrence of PG include minor trauma, chronic irritation, infection, viral oncogenes, increased levels of female sex-hormones (e.g. pregnancy), microscopic arteriovenous anastomoses and drugs (e.g. retinoids) [1] [2].

Although spontaneous resolution of PG is possible, therapy is usually necessary. A variety of therapeutic regimens have been used in the management of PG, with variable success and recurrence rates [3], including surgical and shave excision, curettage, electrodessication, laser therapy, cryotherapy, radiotherapy, sclerotherapy, topical and systemic steroids, microembolization, topical timolol or imiquimod and intralesional bleomycin [4] [5].

In the present paper we report the case of a 9-year-old boy with suborbital pyogenic granuloma, which was successfully treated with topical application of imiquimod $5 \%$ cream.

\section{Case Report}

A previously healthy 9-year-old boy presented with a three-week history of a solitary vascular lesion that had developed on his facial skin subsequent to minor trauma. Physical examination showed a healthy-looking boy with normal growth and development. In his right suborbital region, $1.2 \mathrm{~cm}$ under his lower eyelid, there was a red-violet spherical nodule with a diameter of $4 \mathrm{~mm}$ (Figure 1(a)) that was clinically consistent with pyogenic granuloma. The results of routinely performed laboratory investigations were either negative or within normal range. The parents of the patient were informed about the existing therapeutic options (described in the Introduction) and the possible side effects, declined the surgical excision of the lesion and gave their written consent for its topical treatment with imiquimod 5\% cream once daily without occlusion. Considering the proximity of the lesion to the patient's eye, we chose this therapeutic approach due to its non-invasive nature and the minimal risk of scaring, as compared to tissue-destructive procedures. Already after 3 days of treatment, a progressive inflammation with swelling of the lesion and perilesional erythema became evident, whereas spontaneous bleeding with formation of hemorrhagic crusts has repeatedly occurred in the second and third week of treatment (Figure 1(b)). Thereafter, despite further topical application of imiquimod there was a progressive shrinking of the lesion (Figure 1(c)).

Finally, 8 weeks after onset of treatment a complete resolution of the lesion without any scarring was observed (Figure $1(\mathrm{~d})$ ). No systemic side effects were seen and the patient remained well throughout the course of therapy. He is presently completing a 15-month follow-up and has revealed no relapse. The parents of the patient gave their written consent for this case report to be published.

\section{Discussion}

Imiquimod, representative of the imidazoquinoline family of immune response modifiers, is a topically applicable TLR-7/8 agonist known to stimulate the $\mathrm{cu}$ taneous innate immunity and the cellular arm of the adaptive immune response 


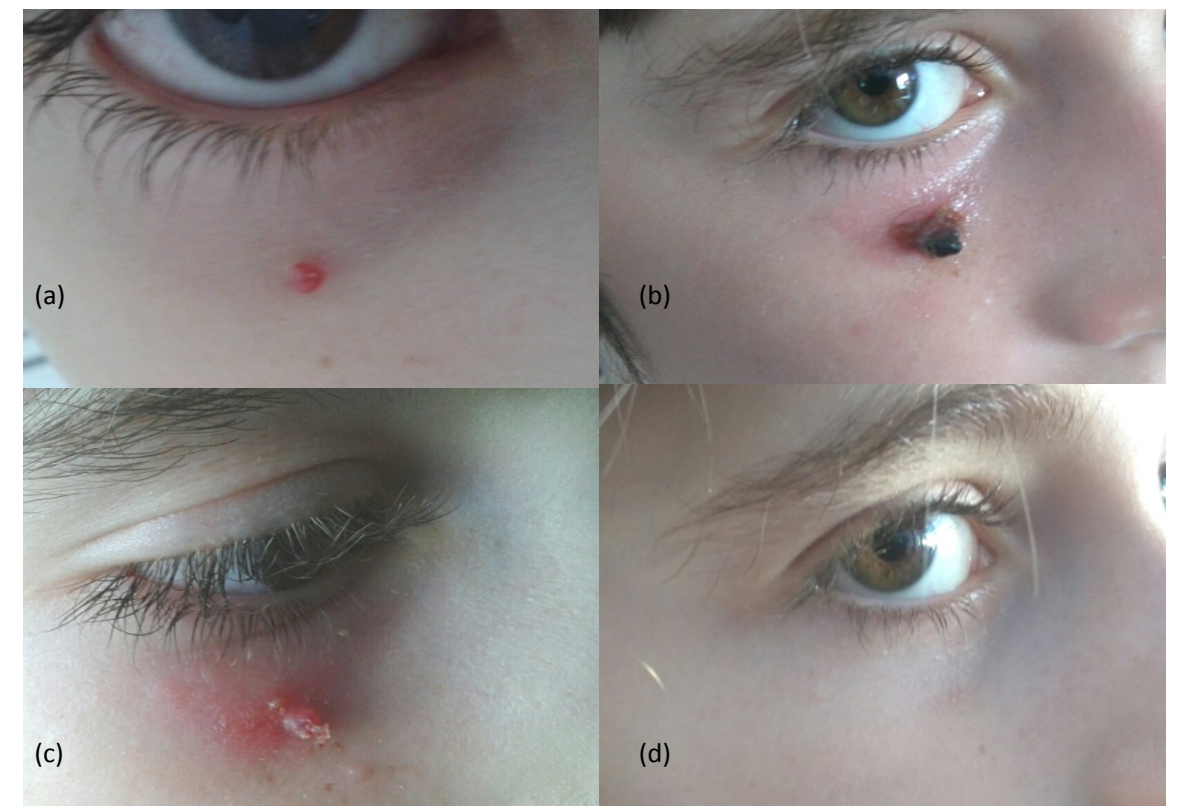

Figure 1. (a) Clinical aspect of the suborbital pyogenic granuloma prior to onset of therapy; (b) Hemorrhagic crust formation after 2 weeks of therapy; (c) Progressive shrinking of the lesion after 5 weeks of therapy; (d) Complete resolution of pyogenic granuloma after 8 weeks of topical treatment with imiquimod $5 \%$ cream once daily without occlusion.

and to exerting potent antiviral, antitumor, antiangiogenic and immunoregulatory effects [5] [6] [7]. These actions are accomplished, at least in part, through secretion of pro-inflammatory cytokines by monocytes, macrophages and dendritic cells, subsequent to drug's binding to Toll-like receptors [8].

Imiquimod is approved for the treatment of external genital and perianal warts in adults, basal cell carcinomas and actinic keratoses. It is also used for a variety of off-label indications including cutaneous viral infections and neoplasms [9]. Our team demonstrated for the first time that topical application of imiquimod induces systemic immunomodulation and significant alterations in peripheral blood lymphocyte subsets of healthy individuals [7]. We also successfully used imiquimod in the treatment of various skin disorders including pyogenic granuloma, herpes labialis, lichen striatus, granuloma annulare and molluscum contagiosum [10]-[15].

Although the pathogenetic mechanisms of PG are far from been fully understood, there is accumulating evidence suggesting an imbalance between angiogenesis enhancers(increased expression of vascular endothelial growth factor, basic fibroblast growth factor and decorin) and angiogenesis inhibitors (reduced expression of angiostatin) [16] [17]. A recent genetic study on vessels derived from cutaneous PG lesion identified a gene signature including genes of the nitric oxide pathway and those related to hypoxia-induced angiogenesis and vascular injury, like the tyrosine-kinase receptor FTL4 [18]. Thus, PG may be regarded as a reactive lesion resulting from tissue injury, followed by an impaired wound healing response, during which vascular growth is driven by FLT4 and the nitric oxide pathway. 
Imiquimod, apart from its immunomodulatory effects, also exerts potent antiangiogenic activity [12] [19] [20] due to induction of antiangiogenic cytokines (interferons $\alpha, \beta$ and $\gamma$, and interleukins 10, 12 and 18), promotion of endothelial cell apoptosis, downregulation of proangiogenic factors (FGF-2 and matrix metalloproteinase-9) and upregulation of endogenous inhibitors of angiogenesis (thrombospondin-1 and tissue inhibitor of matrix metalloproteinase-1). These antiangiogenic effects could probably restore the upregulated neovascularization observed in PG and contribute to the therapeutic action of imiquimod.

In our case, a 9 year-old boy with a PG located $1.2 \mathrm{~cm}$ under his lower eyelid, topical treatment with imiquimod (once daily without occlusion) led to a complete remission of the lesion within 8 weeks and to an excellent cosmetic result. Besides the expected inflammatory reaction of the resolving lesion, moderate erythema was observed in the perilesional skin, whereas no systemic side-effects were seen. The patient is presently completing a 15-month follow-up and has revealed no relapse.

Successful treatment of PG with imiquimod in children has been previously reported [21] [22] [23] [24] [25]. However, only one paper on imiquimod treatment of PG lesion with suborbital localization has been published [21].

\section{Conclusion}

Our findings taken together with those of the literature suggest that imiquimod is a safe, effective and well-tolerated treatment for PG, even at difficult to treat areas like the suborbital region. This is of particular importance in pediatric patients whose parents usually refuse invasive treatment options for which general anesthesia is often required.

\section{References}

[1] Armstrong, K. and Weinstein, M. (2011) Pyogenic Granulomas during Isotretinoin Therapy. Journal of Dermatological Case Reports, 5, 5-7. https://doi.org/10.3315/jdcr.2011.1062

[2] Lin, R.L. and Janniger, C.K. (2004) Pyogenic Granuloma. Cutis, 74, 229-233.

[3] Ghodsi, S.Z., Raziei, M., Taheri, A., Karami, M., Mansoori A. and Farnaghi, F. (2006) Comparison of Cryotherapy and Curettage for the Treatment of Pyogenic Granuloma: A Randomized Trial. British Journal of Dermatology, 154, 671-675.

[4] Lee, J., Sinno, H., Tahiri, Y. and Gilardino, M.S. (2011) Treatment Options for Cutaneous Pyogenic Granulomas: A Review. Journal of Plastic, Reconstructive \& Aesthetic Surgery, 64, 1216-1220. https://doi.org/10.1016/j.bjps.2010.12.021

[5] Bilu, D. and Sauder, D.N. (2003) Imiquimod: Modes of Action. British Journal of Dermatology, 149 (Suppl. 66), 5-8.

[6] Schön, M.P. and Schön, M. (2004) Immune Modulation and Apoptosis Induction: Two Sides of the Antitumoral Activity of Imiquimod. Apoptosis, 9, 291-298. https://doi.org/10.1023/B:APPT.0000025805.55340.c3

[7] Pasmatzi, E., Chaidaroglou, A., Sakkis, T., Monastirli, A., Georgiou, S., Sagriotis, A., Matsouka, P., Degiannis, D. and Tsambaos, D. (2009) Topical Application of Imiquimod Induces Alterations in Peripheral Blood Lymphocytes in Healthy Individu- 
als. Acta Dermato-Venereologica, 89, 134-139.

[8] Urosevic, M., Oberholzer, P.A., Maier, T., Hafner, J., Laine, E. and Slade, H. (2004) Imiquimod Treatment Induced Expression of Opioid Growth Factor Receptor: A Novel Tumor Antigen Induced by Interferon-Alpha. Clinical Cancer Research, 10, 4959-4970. https://doi.org/10.1158/1078-0432.CCR-04-0193

[9] Hennge, U.R. and Ruzicka, T. (2004) Topical Immunomodulation in Dermatology: Potential of Toll-Like Receptor Agonists. Dermatologic Surgery, 30, 1101-1112. https://doi.org/10.1097/00042728-200408000-00008

[10] Badavanis, G., Monastirli, A., Pasmatzi, E. and Tsambaos, D. (2005) Successful treatment of Granuloma Annulare with Imiquimod Cream 5\%: A Report of Four Cases. Acta Dermato-Venereologica, 85, 547-548.

[11] Tsambaos, D., Chaidaroglou, A, Sakkis, Th., Sagriotis, A., Georgiou, S., Badavanis G., Pasmatzi, E., Monastirli, A., Matsouka P. and Degiannis, D. (2006) Topical Toll-Like Receptor Agonists: A New Era in Cutaneous Immunotherapy. Review of Clinical Pharmacology and Pharmacokinetics, 20, 341-343.

[12] Georgiou, S., Monastirli, A, Pasmatzi, E. and Tsambaos, D. (2008) Pyogenic Granuloma: Complete Remission under Occlusive Imiquimod 5\% Cream. Clinical and Experimental Dermatology, 33, 454-456. https://doi.org/10.1111/j.1365-2230.2007.02677.x

[13] Monastirli, A., Melachrinou, M., Pasmatzi, E., Georgiou, S. and Tsambaos, D. (2010) Successful Treatment of Lichen Striatus with Occlusive Imiquimod 5\% Cream. Hospital Chronicles, 5, 33-35.

[14] Tsambaos, D., Rodi, M., Pasmatzi, E., Monastirli, A., Papadaki, H. and Mouzaki, A. (2011) Long-Term Remission of Recurrent Herpes Labialis Following Topical Imiquimod Application on Distal Healthy Skin: A Clinical and Immunological Study. Antiviral Therapy, 16, 863-869. https://doi.org/10.3851/IMP1793

[15] Badavanis, G., Pasmatzi, E., Monastirli, A., Georgiou, S. and Tsambaos, D. (2017) Topical Imiquimod Is an Effective and Safe Drug for Molluscum Contagiosum in Children. Acta Dermatovenerologica Croatica, 25, 165-166.

[16] Yuan, K., Jin, Y.T. and Lin, M.T. (2000) The Detection and Comparison of Angiogenesis-Associated Factors in Pyogenic Granuloma by Immunohistochemistry. Journal of Periodontology, 71, 701-709. https://doi.org/10.1902/jop.2000.71.5.701

[17] Nelimarkka, L., Salminen, H., Kuopio, T., Nikkari, S., Ekfors, T. and Laine, J. (2001) Decorin Is Produced by Capillary Endothelial Cells in Inflammation-Associated Angiogenesis. American Journal of Pathology, 158, 345-353. https://doi.org/10.1016/S0002-9440(10)63975-2

[18] Godfraind, C., Calicchio, M.L. and Kozakewich, H. (2013) Pyogenic Granuloma, an Impaired Wound Healing Process, Linked to Vascular Growth Driven by FLT4 and the Nitric Oxide Pathway. Modern Pathology, 26, 247-255. https://doi.org/10.1038/modpathol.2012.148

[19] Hesling, C., D'Incan, M., Mansard, S., Franck, F., Corbin-Duval, A. and Chèvenet, C. (2004) In Vivo and in Situ Modulation of the Expression of Genes Involved in Metastasis and Angiogenesis in a Patient Treated with Topical Imiquimod for Melanoma Skin Metastases. British Journal of Dermatology, 150, 761-767. https://doi.org/10.1111/j.0007-0963.2004.05898.x

[20] Li, V.W., Li, W.W., Talcott, K.E. and Zhai, A.W. (2005) Imiquimod as an Antiangiogenic Agent. Journal of Drugs in Dermatology, 4, 708-717.

[21] Fallah, H., Fischer, G. and Zagarella, S. (2007) Pyogenic Granuloma in Children: Treatment with Topical Imiquimod. Australasian Journal of Dermatology, 48, 
217-220. https://doi.org/10.1111/j.1440-0960.2007.00389.x

[22] Tritton, S.M., Smith, S., Wong, L.C., Zagarella, S. and Fischer, G. (2009) Pyogenic Granuloma in Ten Children Treated with Topical Imiquimod. Pediatric Dermatology, 26, 269-272. https://doi.org/10.1111/j.1525-1470.2008.00864.x

[23] Gencoglan, G., Inanir, I. and Gündüz, K. (2009) Pyogenic Granuloma in Two Children Successfully Treated with Imiquimod 5\% Cream. Pediatric Dermatology, 26, 366-368. https://doi.org/10.1111/j.1525-1470.2009.00927.x

[24] Mao, X.H., Wang, J.Y. and Yan, J.L. (2009) Topical Imiquimod Treatment of Cutaneous Vascular Disorders in Pediatric Patients: Clinical Evaluation on the Efficacy and Safety. Journal of Zhejiang University. Science B, 13, 745-750. https://doi.org/10.1631/jzus.B1200120

[25] Musumeci, M.L., Lacarrubba, F., Anfuso, R., Li Calzi, M. and Micali, G. (2013) Two Pediatric Cases of Pyogenic Granuloma Treated with Imiquimod 5\% Cream: Combined Clinical and Dermatoscopic Evaluation and Review of the Literature. Giornale Italiano di Dermatologia e Venereologia, 148, 147-152. 